\title{
The effect of glycemic control and renin angiotensin system inhibition on proliferative diabetic retinopathy in streptozotocine induced diabetes: A controlled study of insulin and ACE inhibitor
}

\author{
İnci Güngör*a, Oğuz Aydın ${ }^{b}$, Levent Güngörc \\ ${ }^{a}$ Department of Ophthalmology, Medical Faculty, Ondokuz Mayıs University, Samsun, Turkey \\ ${ }^{b}$ Department of Pathology, Medical Faculty, Ondokuz Mayis University, Samsun, Turkey \\ ${ }^{c}$ Department of Neurology, Medical Faculty, Ondokuz Mayıs University, Samsun, Turkey
}

\begin{tabular}{|c|c|}
\hline \multicolumn{2}{|c|}{ ARTICLE INFO } \\
\hline \multicolumn{2}{|c|}{ Article History } \\
\hline Received & $09 / 06 / 2010$ \\
\hline Accepted & $10 / 06 / 2010$ \\
\hline
\end{tabular}

\section{* Correspondence to: \\ İnci Güngör \\ Ondokuz Mayıs University \\ Medical Faculty \\ Department of Ophthalmology \\ Samsun, Turkey \\ e-mail: ligungor@omu.edu.tr}

\section{Key Words :}

Diabetic retinopathy

Insulin

ACE inhibitors

Streptozotocine induced diabetes

Enalapril

Neovascularisation

\begin{abstract}
Renin-Angiotensin-Aldosteron System, by causing microvascular changes, has an important impact on the pathogenesis of diabetic retinopathy. Drugs inhibiting Angiotensin Converting Enzyme (ACE) have a potential effect on improving neovascularization at retina. In this study, we aimed to determine the probable effect of an ACE inhibitor, enalapril, on the neovascularization at the rat retina in an experimental model of diabetes compared with insulin treatment. Twenty six Wistar rats were included in the study. Streptozotocine was injected into 18 Wistar rats. After a four-week period of diabetes, the rats were separated in to three groups. No medication was given to the first group. Subcutaneous insulin was given to the second group, and oral enalapril to the third group, for seven days. Eight rats were used as the diabetic control group with no procedure. At the end of one week of therapy, the globes were removed and the number of blood vessel profiles which is indicator of neovascularisation under the internal limiting membrane were counted. The difference between groups was investigated statistically. The number of blood vessel profiles was significantly lower in the control rats than in the streptozotocine injected groups $(p<0.001)$. The number of blood vessel profiles was lower in the enalapril group than in the no treatment group but was not statistically significant $(\mathrm{p}>0.05)$. The number of blood vessel profiles was significantly lower in the insulin group than the no treatment group $(\mathrm{p}<0.01)$. Insulin and good glycemic control are more effective than the ACE inhibitor enalapril in the treatment of diabetic proliferative retinopathy.
\end{abstract}

J. Exp. Clin. Med., 2010; 27:26-30

\section{Introduction}

The relationship between diabetic microvascular complications and the Renin-Angiotensin-Aldosteron System (RAS) has been known for years. Diabetic retinopathy is one of the most frequent microvascular complications of diabetes. Angiotensin-I is changed to Angiotensin-II by the Angiotensin Converting Enzyme (ACE). Angiotensin-II is a very strong vasoconstrictor agent that increases blood pressure and effects the secretion of aldosterone from the kidneys (Danser et al.,1994). Angiotensin-II also induces microvascular changes that lead to diabetic retinopathy (Kato et al.,1991; Gutierrez et al., 1997; Kimura et al., 1998). Pharmacological agents that reduce the levels of Angiotensin-II by inhibiting RAS may be useful for preventing and treating diabetic retinopathy. A few studies show the beneficial effects of ACE inhibitors and good glycemic control on diabetic retinopathy. In this research, we investigated the potential effects of the ACE inhibitor enalapril and on diabetic retinopathy compared with insulin treatment in a streptozotocine-induced model.

\section{Materials and Methods}

The experiment was approved by the local ethics committee of surgical research. Twenty-six Wistar rats that were 4-6 months old and weighed 159-224 grams were included in the study. Normoglycemia was demonstrated by spectrophotometry in the blood samples from the tail veins (Accu-Chek Active Glucometer). Fifty mg/ $\mathrm{kg}$ streptozotocine (Serva Electrophoresis) dissolved in isotonic sodium chloride buffer was injected into 18 rats intraperitoneally. Eight rats without streptozotocine injection were used as non-diabetic control group for the further histopathological investigation of the retina. The 
animals were observed for four weeks in plastic cages, one rat per cage. They were let free at libidum for water and foot. They were provided with 12 hours of daylight and 12 hours of darkness each day. All the cages were kept at room temperature.

At the end of the fourth week, blood glucose levels were measured again by the same method to check for hyperglycemia. All 18 rats were weighted and separated into three groups, each of which consisted of six rats. The six rats in the first group were observed in their cages with no medication (no treatment group) for seven days. Twenty-four IU/kg 70/30 mixtard insulin (Lilly) was injected to the second group daily between 9:00 a.m. and 11:00 a.m. for seven days (insulin group). A single $6 \mathrm{mg} / \mathrm{kg}$ dose of enalapril maleat was dissolved in $0.5 \mathrm{cc}$ distillated water and given daily by gastric gavages to the third group (enalapril group) between 9:00 a.m. and 11:00 a.m. for seven days. At the end of one the first week, all the rats were killed and both eyes were rapidly removed. The eyes of the eight rats without streptozotocine injection or any other treatment were enucleated to compare normal retina and were considered as the non-diabetic control group.

The globes were fixed for 12 hours in $10 \%$ buffered formalin. For microscopic examination of the retina, one slice was prepared from a single eye. The slices were taken from the thickest portion of the bulbous ocular, as close as possible to the optic nerve. The slices were prepared according to routine tissue processing protocols and paraffin blocks were sectioned at 4-5 micrometers and stained with hematoxylin eosin for histopathological evaluation and with antihuman CD31 (monoclonal mouse antihuman antibody, clone no 1A10 Novocastra Laboratories Limited, Newcastle, UK) antibodies for immunhistochemical evaluation. The avidin-biotin immunoperoxidase complex technique was used for immunhistochemical evaluation. All the slides were examined by the same pathologist who was blind to the groups.

Immunhistochemical staining with anti CD31, which is specific for the endothelial cells, was used to make the capillary bed more visible. For the numeric definition of neovascularization at the retina, the technique previously described by Moravsky et al was used (Moravski et al., 2000) Blood Vessel Profiles (BVFs) are defined as a single endothelial cell gaining CD31 stain and having a lumen that forms a capillary vessel. The BVPs under internal limiting membrane at each microscopic area with $\times 400$ magnification were counted to determine the extent of neovascularization in the retinas. The number of BVPs in different microscopic sections at each slice was compared between the four groups. ANOVA and Post Hoc Tukey HSD tests were used for the statistical evaluation.

\section{Results}

All the rats were normoglycemic before being injected with streptozotocine $(70-160 \mathrm{mg} / \mathrm{dl})$. The blood glucose level in all 18 experimental rats was higher than $200 \mathrm{mg} / \mathrm{dl}$ four weeks after the injection (mean $335.83 \mathrm{mg} / \mathrm{dl}$, range:
210-599 mg/dl). All subjects completed the four-week diabetic period and one-week treatment period with no complications.

At the end of the fifth week, the blood glucose levels of the enalapril and no treatment groups did not differ significantly $(\mathrm{p}>0.05)$. All the rats were still hyperglycemic and mean blood glucose level were 225.83 $\pm 20.07 \mathrm{mg} / \mathrm{dl}$ for enalapril group and $323.83 \pm 113.81$ $\mathrm{mg} / \mathrm{dl}$ for the no treatment group. After one week of treatment with insulin, the blood glucose levels decreased significantly (mean $105.00 \pm 69.20 \mathrm{mg} / \mathrm{dl}, \mathrm{p}<0.01$ ). Five rats in the insulin group had normalized blood glucose levels and one had still high blood glucose $(234 \mathrm{mg} / \mathrm{dl}$, which was reduced from $469 \mathrm{mg} / \mathrm{dl}$ ). Additionally, the rats in the insulin group gained significant weight $(p<0.05)$. There was no change in the body weights of the enalapril and control groups after one week of treatment ( $p>0.05)$. Table 1: The list of the numbers of blood vessel profiles on each microscopic area in the rat retinas, and the total number of microscopic section investigated.

\begin{tabular}{|c|c|c|c|c|c|c|c|c|c|c|c|c|c|c|}
\hline Groups & \multirow{2}{*}{$\begin{array}{c}\begin{array}{c}\text { Subj. } \\
\text { no }\end{array} \\
1 \\
\end{array}$} & Eye & \multicolumn{11}{|c|}{ BVPs on each microscopic sections } & $\begin{array}{c}\text { Number of } \\
\text { mic.sec. }\end{array}$ \\
\hline \multirow{12}{*}{$\begin{array}{l}\text { no } \\
\text { treatment } \\
\text { group }\end{array}$} & & $\mathrm{R}$ & 2 & 2 & & 3 & 2 & 2 & & & & & & \multirow{12}{*}{70} \\
\hline & 1 & L & 3 & 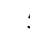 & & 5 & 4 & 5 & 4 & 3 & & 4 & & \\
\hline & 2 & $\mathrm{R}$ & 7 & 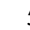 & & 3 & 3 & 4 & & & & & & \\
\hline & 2 & L & 4 & 2 & & & & & & & & & & \\
\hline & 3 & $\mathrm{R}$ & 3 & 2 & & 3 & 2 & 4 & 3 & 5 & & 3 & & \\
\hline & 3 & $\mathrm{~L}$ & 5 & ( & & & & & & & & & & \\
\hline & 4 & $\mathrm{R}$ & 3 & 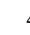 & & 3 & 2 & 4 & 4 & & & & & \\
\hline & 4 & $\mathrm{~L}$ & 3 & & & 4 & 5 & 3 & 4 & 7 & & 6 & & \\
\hline & 5 & $\mathrm{R}$ & 4 & & & 8 & & & & & & & & \\
\hline & 5 & $\mathrm{~L}$ & 5 & & & 8 & 10 & 4 & 7 & 5 & & 5 & 5 & \\
\hline & 6 & $\mathrm{R}$ & 8 & & & 2 & 4 & 4 & 2 & 3 & & 7 & 4 & \\
\hline & 6 & L & 2 & & & 5 & 4 & 6 & & & & & & \\
\hline \multirow{12}{*}{$\begin{array}{l}\text { insulin } \\
\text { group }\end{array}$} & 7 & $\mathrm{R}$ & 2 & 2 & 3 & 1 & 2 & 1 & & & & \multirow{12}{*}{\multicolumn{2}{|c|}{53}} & \multirow{12}{*}{83} \\
\hline & 7 & $\mathrm{~L}^{*}$ & & & & & & & & & & & & \\
\hline & 8 & $\mathrm{R}$ & 3 & 3 & 4 & 5 & 5 & 3 & & & & & & \\
\hline & 8 & $\mathrm{~L}$ & 6 & 4 & 3 & 4 & 5 & 5 & 4 & 5 & & & & \\
\hline & 9 & $\mathrm{R}$ & 6 & 4 & 4 & 5 & 3 & 3 & 5 & 6 & 5 & & & \\
\hline & 9 & L & 6 & 3 & 5 & 3 & 2 & 4 & 3 & 4 & 3 & & & \\
\hline & 10 & $\mathrm{R}$ & 3 & 3 & 4 & 4 & 4 & 7 & 6 & & & & & \\
\hline & 10 & L & 3 & 2 & 2 & 5 & 3 & & & & & & & \\
\hline & 11 & $\mathrm{R}$ & 3 & 2 & 2 & 2 & 2 & 1 & 1 & 3 & & & & \\
\hline & 11 & L & 2 & 3 & 3 & 3 & & & & & & & & \\
\hline & 12 & $\mathrm{R}$ & 3 & 2 & 3 & 4 & 5 & 3 & 5 & 2 & 2 & & & \\
\hline & 12 & L & 3 & 2 & 3 & 4 & 4 & 3 & 2 & 3 & 2 & 3 & & \\
\hline \multirow{12}{*}{$\begin{array}{c}\text { enalapril } \\
\text { group }\end{array}$} & 13 & $\mathrm{R}$ & 4 & 4 & 4 & 3 & 4 & 5 & 4 & 3 & 5 & & & \multirow{12}{*}{75} \\
\hline & 13 & L & 3 & 5 & 4 & 5 & 4 & 7 & & & & & & \\
\hline & 14 & $\mathrm{R}$ & 4 & 4 & 5 & 3 & 4 & 3 & 3 & 5 & 4 & & & \\
\hline & 14 & L & 7 & 5 & 3 & 3 & 2 & & & & & & & \\
\hline & 15 & $\mathrm{R}$ & 2 & 5 & 5 & 6 & & & & & & & & \\
\hline & 15 & L & 5 & 3 & 1 & 3 & 2 & 3 & 2 & & & & & \\
\hline & 16 & $\mathrm{R}$ & 6 & 3 & 2 & 4 & 3 & 4 & & & & & & \\
\hline & 16 & L & 4 & 4 & 3 & 5 & 5 & 2 & 2 & 2 & 1 & & & \\
\hline & 17 & $\mathrm{R}$ & 4 & 2 & 4 & 3 & 3 & 3 & 3 & 2 & 2 & & & \\
\hline & 17 & L & 3 & 4 & 4 & 5 & 5 & 4 & 6 & & & & & \\
\hline & 18 & $\mathrm{R}$ & 6 & 2 & 5 & 4 & & & & & & & & \\
\hline & 18 & $\mathrm{~L}^{*}$ & & & & & & & & & & & & \\
\hline \multirow{16}{*}{$\begin{array}{c}\text { Control } \\
\text { group }\end{array}$} & 19 & $\mathrm{R}$ & 2 & 2 & 3 & 1 & & & & & & & & \multirow{16}{*}{114} \\
\hline & 19 & $\mathrm{~L}$ & 2 & 2 & 4 & 1 & 2 & 2 & 2 & 1 & 2 & & 1 & \\
\hline & 20 & $\mathrm{R}$ & 3 & 3 & 2 & 1 & 1 & 1 & 2 & 1 & 2 & 1 & & \\
\hline & 20 & L & 2 & 2 & 1 & 2 & 3 & 1 & & & & & & \\
\hline & 21 & $\mathrm{R}$ & 1 & 1 & 2 & 2 & 7 & 2 & 2 & 3 & & & & \\
\hline & 21 & L & 1 & 1 & 2 & 1 & 2 & 1 & 1 & & & & & \\
\hline & 22 & $\mathrm{R}$ & 3 & 3 & 2 & 2 & 1 & 2 & 2 & 2 & & & & \\
\hline & 22 & L & 3 & 2 & 2 & 1 & 1 & 2 & 2 & & & & & \\
\hline & 23 & $\mathrm{R}$ & 2 & 2 & 3 & 1 & 2 & 3 & 2 & 2 & & & & \\
\hline & 23 & L & 2 & 2 & 2 & 1 & & & & & & & & \\
\hline & 24 & $\mathrm{R}$ & 2 & 2 & 1 & 1 & 1 & 2 & 2 & 1 & 2 & & & \\
\hline & 24 & L & 1 & 2 & 2 & 2 & 1 & 2 & 1 & & & & & \\
\hline & 25 & $\mathrm{R}$ & 2 & 1 & 2 & 2 & 2 & 2 & & & & & & \\
\hline & 25 & L & 2 & 2 & 1 & 2 & 1 & 3 & 2 & 1 & & & & \\
\hline & 26 & $\mathrm{R}$ & 3 & 2 & 2 & 1 & 2 & 1 & 2 & & 2 & 2 & & \\
\hline & 26 & $\mathrm{~L}^{*}$ & & & & & & & & & & & & \\
\hline
\end{tabular}

( BVP: Blood Vessel Profiles, Subj:Subject, mic.sec. microscopic sections., R:right, L:left, *: unsuitable slides. ) 
Forty-nine slices from 52 eyes were suitable for the microscopic investigation ( 12 slices from the no treatment group, 11 slices from the insulin group, 11 from the enalapril group, and 15 slices from the non-diabetic control group). The microscopic sections available for the investigation ranged from 2 to 11 from each specimen. The BVPs under the internal limiting membrane of the retina were counted at 70 microscopic sections from 12 slices of the no treatment group, 83 microscopic sections from 11 slices of the insulin group, 75 microscopic sections from 11 slices of the enalapril group, and 114 microscopic sections from 15 slices of the non-diabetic control group (Table 1).

The mean of BVPs were $1.86 \pm 0.8$ in the nondiabetic control group, $3.40 \pm 1.3$ in the insulin group, $3.73 \pm 1.3$ in the enalapril group and $4.15 \pm 1.7$ in the no treatment group (Table 2).

Table 2: The mean BVPs numbers in groups and $p$ values are shown (BVPs: Blood Vessel Profiles).

\begin{tabular}{|l|c|c|c|c|c|}
\hline & mean \pm SD & \multicolumn{4}{|c|}{ p values between groups } \\
\hline & & control & insulin & enalapril & no treatment \\
\hline Control & $1.86 \pm 0.83$ & $\mathrm{x}$ & $<0.001$ & $<0.001$ & $<0.001$ \\
Insulin & $3.40 \pm 1.34$ & $<0.001$ & $\mathrm{x}$ & $>0.05$ & $<0.01$ \\
Enalapril & $3.73 \pm 1.32$ & $<0.001$ & $>0.05$ & $\mathrm{x}$ & $>0.05$ \\
No treatment & $4.15 \pm 1.72$ & $<0.001$ & $<0.01$ & $>0.05$ & $\mathrm{x}$ \\
\hline
\end{tabular}

In the non diabetic control group, number of BVPs was significantly lower than in the other three groups $(p<0.001)$. This revealed that four week period is sufficient for the development of neovascularisation in the retina after streptozotocine injection. Among the subjects with hyperglycemia, the number of BVPs was significantly higher in the no treatment group compared with the insulin group $(\mathrm{p}<0.01)$. The number of BVPs was lower in the enalapril group than in the no treatment group, but was not statistically significant $(\mathrm{p}>0.05)$. There was no significant difference between the insulin and the enalapril groups $(\mathrm{p}>0.05)$ (Table 2)

\section{Discussion}

Diabetic retinopathy is one of the most frequent causes of blindness worldwide. The best way to prevent retinopathy is intensive blood glucose control. However, for several years investigators have tried to discover a new drug to prevent and improve the microvascular complications of diabetes.

The inhibition of RAS is beneficial for the cardiovascular and nephrologic complications of diabetes mellitus (Burnier and Zanchi, 2006). Some of the histopathological changes in diabetic nephropathy improved slightly with enalapril when given for four weeks in streptozotocine-induced model of diabetes in rats (Itoh et al., 2002). Previous clinical and experimental studies reveal that RAS can be responsible for the pathogenesis of diabetic retinopathy at different stages (Clermont et al., 2006). Pradhan et al found no effect of low doses of ACE inhibitors on the worsening of diabetic retinopathy from mild to moderate grade (Pradhan et al., 2002). In 1996,
Ottlecz and Bensaula followed streptozotocine-injected rats for about two to four months with captopril, and showed that the Na-K ATPase activity increased with this drug in the retina. These observers claim that the ACE inhibitors not only block the activity of RAS system on the tissues, but are responsible for recovery from diabetic retinopathy (Ottlecz and Bensaula, 1996). In another study, lisinopril decreased vascular endothelial cellular proliferation in diabetic-Ren 2 rats (Moravski et al., 2003). Perindopril also decreases the excretion of the vascular endothelial growth factor (VEGF) gene protein product in the retinas of streptozotocine-injected rats, and decreases the retinal permeability in an experimental diabetes model (Gilbert et al., 2000).

Some clinical studies are related to the effects of inhibiting RAS on diabetic retinopathy. The most important of these are the EUCLID and ABCD studies (Chaturvedi et al., 1998; Clermont et al., 2006). In the EUCLID study, which was performed on normotensive diabetic patients, lisinopril and a placebo were given to two groups and patients were followed for two years. At the end of two years, the progression of diabetic retinopathy decreased about $50 \%$ in the lisinopril patients (Chaturvedi et al.,1998; Funatsu and Yamashita, 2003). In the HOPE study, ramipril reduced the risk of laser therapy in diabetic patients (Cordonnier et al., 2001). In the UKPDS study, ACE inhibitors and $\beta$-blockers were similarly effective in reducing the progression of proliferative diabetic retinopathy among type 2 diabetic patients with hypertension.

The UKPDS and WESDR studies confirm that Angiotensin II is an important factor in the development of microvascular complications of diabetes (Funatsu and Yamashita, 2003). Besides elevating blood pressure, Angiotensin II may induce microangiopathy by causing proliferation of vascular wall smooth muscle cells and endothelial cells (Ottlecz and Besaoula, 1996; Gutierrez et al., 1997). It also leads to vascular wall thickening by increasing the excretion of extracellular matrix proteins and to direct vascular damage by increasing plasminogen activator inhibitor-1 (PAI-1) (Kato et al., 1991; Kimura et

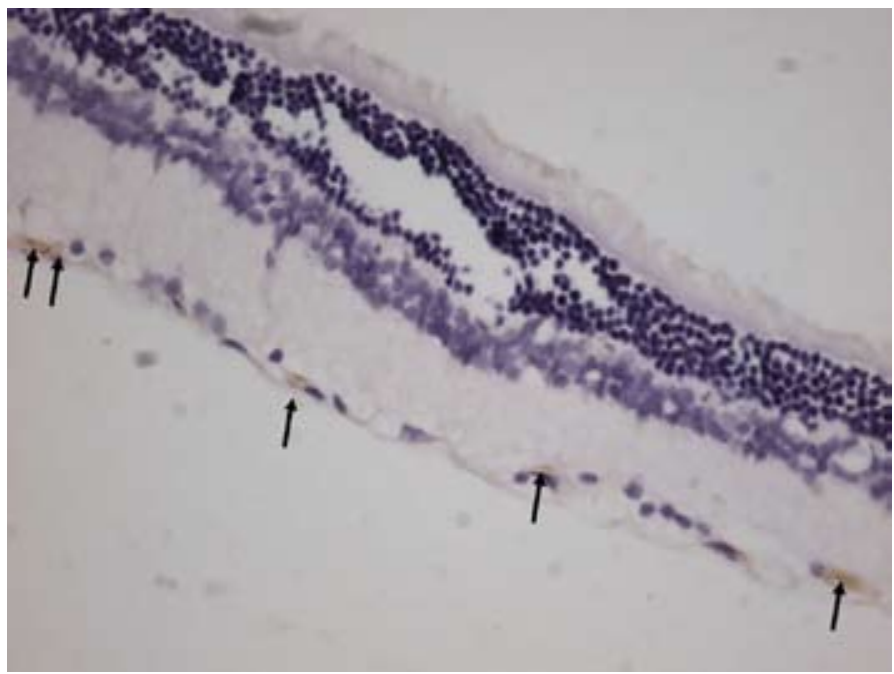

Fig. 1: The CD31 staining image of the retina of the right eye of subject 20 in the control group. Blood vessels with stained endothelial cells are showed with arrows. (Avidin Biotin Complex, X 400 ) 
al.,1998). Angiotensin II increases the excretion of VEGF, which seems to be important in the development of diabetic neovascularization (Cordonnier et al., 2001). Many case series that have shown regression of neovascularization result from diabetic retinopathy with agents of anti-VEGF have been recently published (Grisanti et al., 2006; Mason et al., 2006; Oshima et al., 2006; Spaide and Fisher, 2006).

The gold standard for preventing diabetic retinopathy is insulin treatment (Vaag, 2006). However, the effect of insulin or any other drug on improving diabetic retinopathy is unclear. In the past few years, several reports have demonstrated the beneficial effects of intravitreal and intracameral application of an anti-VEGF, bavacizumab, which causes proliferative retinopathy to regress (Grisanti et al., 2006; Mason et al., 2006; Oshima et al., 2006; Spaide and Fisher, 2006; Avery, 2006).

In our study, we investigated the effects of an ACE inhibitor enalapril maleat and insulin on improving the neovascularisation in the retina in the experimental model of diabetes induced with streptozotocine. We preferred to count BVPs in the retinas to decide the quantitative degree of neovascularisation. Counting BVPs is an easy and indirect way of determining the degree of neovascularisation in retina. Our results reveal that no treatment, including insulin (which induces normoglycemia) normalizes proliferative retinopathy in the streptozotocine-induced experimental model of diabetes. In addition, our study enabled us to compare the effects oral enalapril with subcutaneous insulin. Our results show that enalapril has no significant effect to improve neovascularisation in experimental diabetic retinopathy, but insulin does. This is in concordance with the previous knowledge that lowering blood glucose with insulin is still the best way of treating diabetic proliferative retinopathy. The limitations of our study are the low number of subjects and short period of treatment. More prolonged treatment with ACE inhibitors may be more helpful for diabetic proliferative retinopathy. Further investigations with larger sample size and longer duration that target the effects of insulin and ACE inhibitors are needed.

In this study, we showed that enalapril, an ACE inhibitor, have no significant effect on proliferative diabetic retinopathy. However, good glycemic control supplied by insulin treatment had statistically significant effect on experimental proliferative diabetic retinopathy. Our results emphasize that insulin is the best drug to prevent and improve proliferative diabetic retinopathy.

\section{ACKNOWLEDGEMENTS}

The statistical analysis for this study are performed by Ahmet Tevfik Sunter (M.D., Assistant Professor, Ondokuz Mayıs University, School of Medicine).

Financial support: This study is supported by the research foundation from Ondokuz Mayis University.

\section{REFERENCES}

Avery, R.L. 2006. Regression of retinal and iris neovascularization after intravitreal bevacizumab (Avastin) treatment. Retina. 26, 352-354.

Burnier, M., Zanchi, A., 2006. Blockade of the rennin-angiotensin-aldosterone system: a key therapeutic strategy to reduce renal and cardiovascular events in patients with diabetes. J. Hypertens. 24, 11-25.

Chaturvedi, N., Sjolie, A., Stephenson, J.M., 1998. Effect of lisinopril on progression of retinopathy in normotensive people with type 1 diabetes. Lancet. 351, 28-31.

Clermont, A., Bursell, S., Feener, E.P. 2006. Role of the angiotensin II type 1 receptor in the pathogenesis of diabetic retinopathy: effects of blood pressure control and beyond. J. Hypertens. 24, 73-80.

Cordonnier, D.J, Zoaui, P., Halimi, S., 2001. Role of ACE inhibitors in patients with Diabetes Mellitus. Drug. 61, 18831892.

Danser, A.H.J., Derkx, F.H.M., Admiraal, P.J.J., Denium, J., Jong, P.T.V.M., Schalekamp, M.A.D.H., 1994. Angiotensin levels in the eye. Invest. Ophthalmol. Vis. Sci.35,1008-1018.

Funatsu, H., Yamashita, H., 2003. Pathogenesis of diabetic retinopathy and the renin-angiotensin system. Ophthal. Physiol. Opt. 23, 495-501.

Gilbert, R.E., Kelly, D.J., Cox, A.J., 2000. Angiotensin-converting enzyme inhibition reduces retinal over expression of vascular endothelial growth factor and hyperpermeability in experimental diabetes. Diabetologia 43, 1360-1367.

Grisanti, S., Biester, S., Peters, S., 2006. Intracameral bevacizumab for iris rubeosis. Am. J. Ophthalmol. 142, 158160.

Gutierrez, C., Vendrell, J., Pastor, R., 1997. Angiotensin I-converting enzyme and angiotensinogen gene polymorphism in non-insulin-dependent diabetes mellitus. Lack of relationship with diabetic nephropathy and retinopathy in a Caucasian Mediterranean population. Metabolism 46, 976-980.

Itoh, Y., Imamura, S., Yamamoto, K., 2002. Chances on endothelin in Streptozotocine-induced diabetic rats: effects of Angiotensin converting enzyme inhibitor, enalapril maleate. J. Endocrinol. 175, 233-239.

Kato, H., Suzuki, H., Tajima, S., 1991. Angiotensin II stimulates collagen synthesis in cultured vascular smooth muscle cells. J. Hypertens. 9, 17-22.

Kimura, H., Gejyo, F., Suzuki, Y., Suzuki, S., Miyazaki, R., Arakawa, M., 1998. Polymorphism of Angiotensin converting enzyme and plasminogen activator inhibitor-1 genes in diabetes and macroangiopathy. Kidney Int. 54, 1659-1669. 
Mason, J.O., Nixon, P.A., White, M.F., 2006. Intravitreal injection of bevacizumab (Avastin) as adjunctive treatment of proliferative diabetic retinopathy. Am. J. Ophthalmol. 142, 685-688.

Moravski, C.J., Kelly, D.J., Cooper, M.E., 2000. Retinal neovascularization is prevented by blockade of the reninangiotensin system. Hypertension. 36,1099-1104.

Moravski, C.J., Skinner, S.L., Stubbs, A.J., 2003. The renin-angiotensin system influences ocular endothelial cell proliferation in diabetes. Am. J. Pathol. 162, 151-160.

Oshima, Y., Sakaguchi, H., Gomi, F., Tano, Y., 2006. Regression of iris neovascularisation after intravitreal injection of bevacizumab in patients with proliferative diabetic retinopathy. Am. J. Ophthalmol. 142, 155-158.

Ottlecz, A., Bensaoula, T., 1996. Captopril ameliorates the decreased $\mathrm{Na}+, \mathrm{K}+$-ATPase activity in the retina of Streptozotocine-induced diabetic rats. Invest. Ophthalmol. Vis. Sci. 37, 1633-1641.

Pradhan, R., Fong, D., March, C., 2002. Angiotensin-converting enzyme inhibition for the treatment of moderate to severe diabetic retinopathy in normotensive type 2 diabetic patients. A pilot study. J. Diabetes. Complications. 16, 377-381.

Spaide, R.F., Fisher, Y.L., 2006. Intravitreal bevacizumab (Avastin) treatment of proliferative diabetic retinopathy complicated by vitreous hemorrhage. Retina. 26, 275-278.

Vaag, A.A., 2006. Glycemic control and prevention of microvascular and macrovascular disease in Steno 2 Study. Endocr. Pract. 12, 89-92. 